\title{
Sustainable Agriculture and Smart Farming
}

\author{
Heike Bach and Wolfram Mauser
}

Tomorrow's challenges of doubling food supply put sustainability of agriculture at one level with ensuring food security. The global food system needs to be resource efficient and at the same time sustainable. Efficient use of water, reduction of soil erosion and degradation to the minimum, minimization of energy input and maximization of yields under uncertain natural conditions are the goal. They pose highest requirements on the underlying information and knowledge infrastructure and make future farming a knowledge business and a very sophisticated management task.

Studies on the global and regional potentials of Earth Observation (EO) in agriculture show that EO can be pivotal. Due to its global capacity to determine information relevant for farming EO can become the global source of future, information driven global agriculture (Mauser et al. 2012). Assimilated into sophisticated environmental management models this EO-derived information will allow to support the whole economic and societal value chain from farmers through food industry to insurance and financial industry in producing food. At the same time, it allows to support society in governing sustainable agriculture through verifiable rules and regulations.

Information driven smart farming is a general trend to be observed in agriculture. Ecologically and economically meaningful measures to improve productivity are applied in smart farming. The technique is based on the principles of Precision Farming, i.e. on the use of GPS-guidance to apply site-specific agricultural measures. But while the focus of Precision Farming was mainly on farming technology to for example allow for auto-steering of tractors and harvesters, the focus of smart

\author{
H. Bach $(\bowtie)$ \\ Remote Sensing in Geosciences, VISTA GmbH, Munich, Germany \\ e-mail: bach@vista-geo.de \\ W. Mauser \\ Department of Geography, University of Munich LMU, Munich, Germany \\ e-mail: w.mauser@1mu.de
}


farming shifts towards a more rounded, holistic approach—going from "highest spatial precision" to "smartest treatment". Thus, typical issues of smart farming are e.g. how much fertilizer is best applied when and where in the field or which plant protection resources are optimal for crop development at each location in the field.

The information challenge agriculture is facing is manifold. High spatial and temporal requirements are posed on a monitoring system since the plots where food is produced are in general quite small. Their size varies largely depending on economic and cultural conditions, but $10-20 \mathrm{~m}$ can be deemed the most suitable spatial observational requirement for an agricultural information system, which satisfies foreseeable future needs. This required spatial resolution also fits with the capabilities and spatial accuracies of site-specific farming, which is determined by the working width of the agricultural machinery: seeders $(5-10 \mathrm{~m})$, spreaders and combine harvesters $(20-40 \mathrm{~m})$. The dynamic growth of agricultural crops, and man-made changes within a few days for example through harvests further make it necessary to update the information flow every few days to one week. However maybe most challenging are the complex information requirements since complex information layers like yield or nitrogen uptake are needed. They are in general no direct EO observable.

Sustainable agriculture and smart farming need data driven information services. These support sustainable and cost-effective agriculture by combining Earth Observation and navigation satellites' input with information from ground sensors to help farmers decide how, when and where to allocate resources for the best economic and ecological results (Fig. 1). As use case showing how this is presently applied in farming practise, the TalkingFields smart farming services will be presented (Bach et al. 2010).

EO has been used for agriculture since the 80th of the last century, however the availability and quality of the satellite data has increased drastically since 2015 with the Copernicus program and its operational feet of satellites. Especially Sentinel-2 and -1 are providing excellent time series of data from which e.g. crop types, biomass development, calamities and farming practices (ploughing, seeding, etc.) can be derived with high accuracy.

The free availability of Landsat's complete data archive that is now supported with Sentinel-2 allows for new data analyses techniques. They make use of very data intensive exploration and data fusion techniques. It is now possible to analyse dozens of satellite images of one farm in order to understand the site-characteristics of each field of the farm and even within the fields. The TalkingFields (TF) Base Map illustrated in Fig. 2 is a good example for this procedure.

\section{Multi-Year Site-Characterization of Fields Using Advanced Data Harvesting Techniques}

The TF Base Map is based on a geo-statistical analysis of multi-year optical data to map the spatial heterogeneity of the growing conditions within the field. It uses all available satellite images of the last 5-10 years and evaluates specific 
multiannual features that can be expressed as relative fertility. Often more than 100 scenes are processed in order to get the best representation of site heterogeneity. Pattern recognition techniques also allow for improved segmentation of the field. The TF Base Map can then be used for improved sampling of soil properties or delineating of management zones. The TF Zone Map optimizes the segmentation for soil sampling tasks. Based on the whole variety of in-field growth conditions, it delineates homogeneous regions and thereby ensures that soil samples are representative, as illustrated in the centre field in Fig. 2.

The TF Base Map opens to the farmer a new view on his fields by displaying the in-field differences much in the same way that crops experience when they turn his inputs into yield. The patterns observed in the Base Map are usually bound to site characteristics, e.g. the water holding capacity of the soil based on differences in soil properties or relief related water status. Even within one single field the small-scale changes of yield formation can easily vary by $\pm 25 \%$. This is often not known to the farmer since conventionally yield data are obtained field wise. Thus these EO based maps are a prerequisite for smart farming in the sense that they inform the farmer of the heterogeneity within his fields.

Besides the trend of moving from analysis of single satellite images to multitemporal stacks of images, also data assimilation has become more prominent. Data assimilation of EO data into process models is already a common practise for weather forecast. METEOSAT data are successfully used in the Numerical Weather Prediction Models to make the forecasts more reliable. This concept can now be

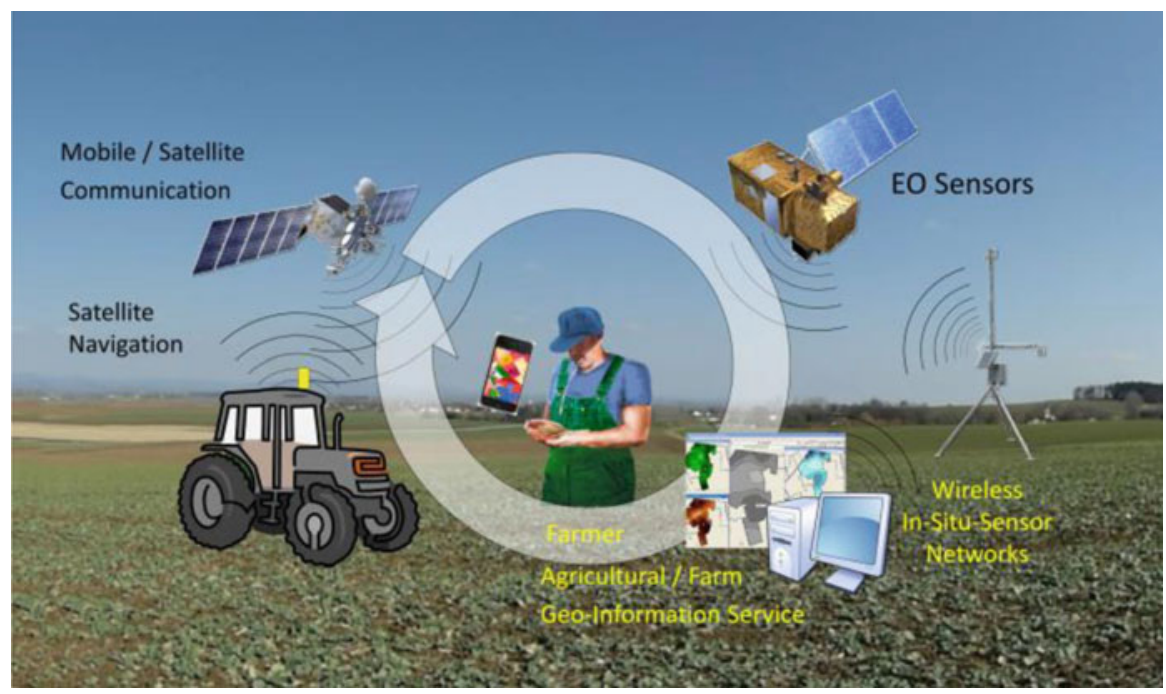

Fig. 1 Information flow in TalkingFields. Space-based components play an essential role in smart farming information services for farmers 


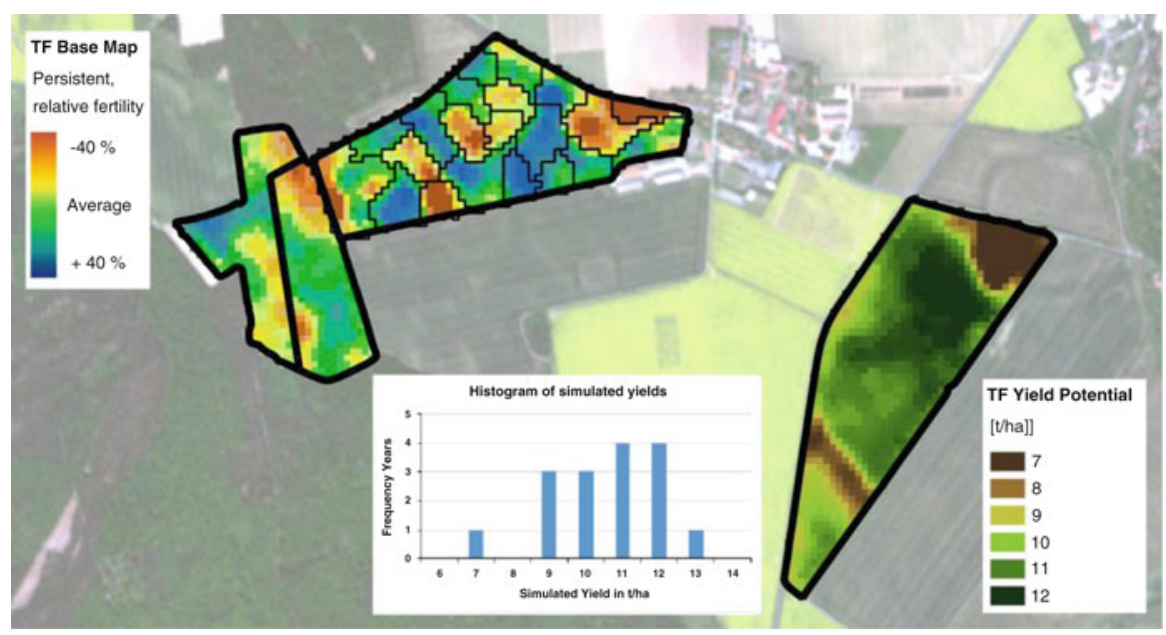

Fig. 2 EO based map products used in smart farming; the TF Base Map offers the persistent relative fertility of a field by analysing satellite images of the last 5-10 years; these TF Base Maps can be segmented in zones for improved (more representative) soil probing; after combining the TF Basemap with crop growth modelling even maps of yield potential can be derived

transferred to high resolution and the land surface generating new products. This is for example the case when extending the information product TF Base Map to a Yield Potential Map.

The yield potential is a quantitative term expressed in $t / h a$ and describes how much yield can be obtained for a field and a specific crop type under the current climatic and topographic conditions assuming no nutrient stress nor pests or diseases. The yield potential is thus also describing the optimum attainable yield if all farming decisions are made correctly. In reality this level is hardly reached and large differences exits in the yield gap that can be calculated from the actual yield and the yield potential.

For obtaining the yield potential the TF Base Map is merged with crop growth simulations of the last 16 years. Using the PROMET crop growth model for each simulated year the potential yield is simulated (for details see also (Mauser et al. 2015)) and the annual results are averaged for the map product illustrated in Fig. 2. In order to also learn about the exposure of the field to climate risks, e.g. droughts, also a histogram analysis of all simulated years is included in the analyses. In this example the variance of yield potential is quite large. In dry years, only $7 \mathrm{t} / \mathrm{ha}$ wheat can be harvested, whereas even $13 \mathrm{t} / \mathrm{ha}$ can be achieved in years with sufficient rainfall. Water is obviously the dominant factor of yield formation in this German region under consideration and accordingly weather risks must be considered rather high. 


\section{Up-to-Date Crop Status Using Access to Satellite Data in Near-Real-Time}

Another trend in Earth Observation is the faster availability of satellite information products. Not only EO data providers offer their data sets in near-real-time, also agricultural information services are now able to generate up-to-date information on crop status within $24 \mathrm{~h}$ after data acquisitions. Information about the current growth status and development of the cultivated crop at each location in the field is deduced from satellite through the derivation of plant parameters such as LAI, biomass and chlorophyll content during the growing season. The up-to-date crop status is used for example for site-specific plant protection and fertilization measures.

TalkingFields also offers this up-to-date information to farmers e.g. with the TF Biomass Map. This map product represents the above ground biomass distribution for a given date. A sequence of Biomass Maps derived from a time series of satellite images documents the temporal and spatial patterns of the biomass development in the observed field. Data assimilation techniques are again needed to enhance the value of satellite data. Accordingly, the TF Yield Maps offer yield information that are determined by combining a plant growth model with time series of multi-sensor EO data. They can be provided already weeks before harvest and validated with at-harvest measurements by a combine.

On the top of Fig. 3 three Biomass Maps can be seen that were assimilated into the agricultural model PROMET to update the daily biomass simulations and nudge the model towards the observed patterns. On the bottom, the resulting yield map can be seen (left side) and compared with the yield map as measured by a GPS-guided combine harvester (right side). It is clearly visible that both yield maps show the same spatial patterns as well as comparable absolute yield values. Since yield is the deciding factor of the farmer's income, a solid validation of the absolute yield values is necessary and was successfully conducted for several years and crop types in Germany (Hank et al. 2015). The yield forecast maps are delivered between 2 and 4 weeks before harvest and give the farmer an overview over the amount of yield expected. If combined with a map of the ripening status, it can also be used to decide where to start with the harvest improving the logistics of harvest machinery.

On-farm research techniques can be used for validating the efficiency and success of precision farming techniques in a realistic scenario (Migdall et al. 2013). Onfarm research results of TalkingFields activities for example showed that reduction of nitrogen input can even coincide with an increase in yield. Yield increase of 3 $6 \%$ could be achieved even on best soils providing a net profit gain to the farmer between 60 and $120 € /$ ha.

Especially Sentinel-2 strongly contributes to these up-to-date agricultural products and related services. Fast and easy access to the satellite data are offered via dedicated data hubs, like ESA's Sentinel-2 hub, or national platforms, like for example CODE-DE as German service offer. Private companies like Amazon offer not only to download data but also allow further processing directly on the platform. Sponsored by ESA, dedicated Thematic Exploitation Platforms are under 


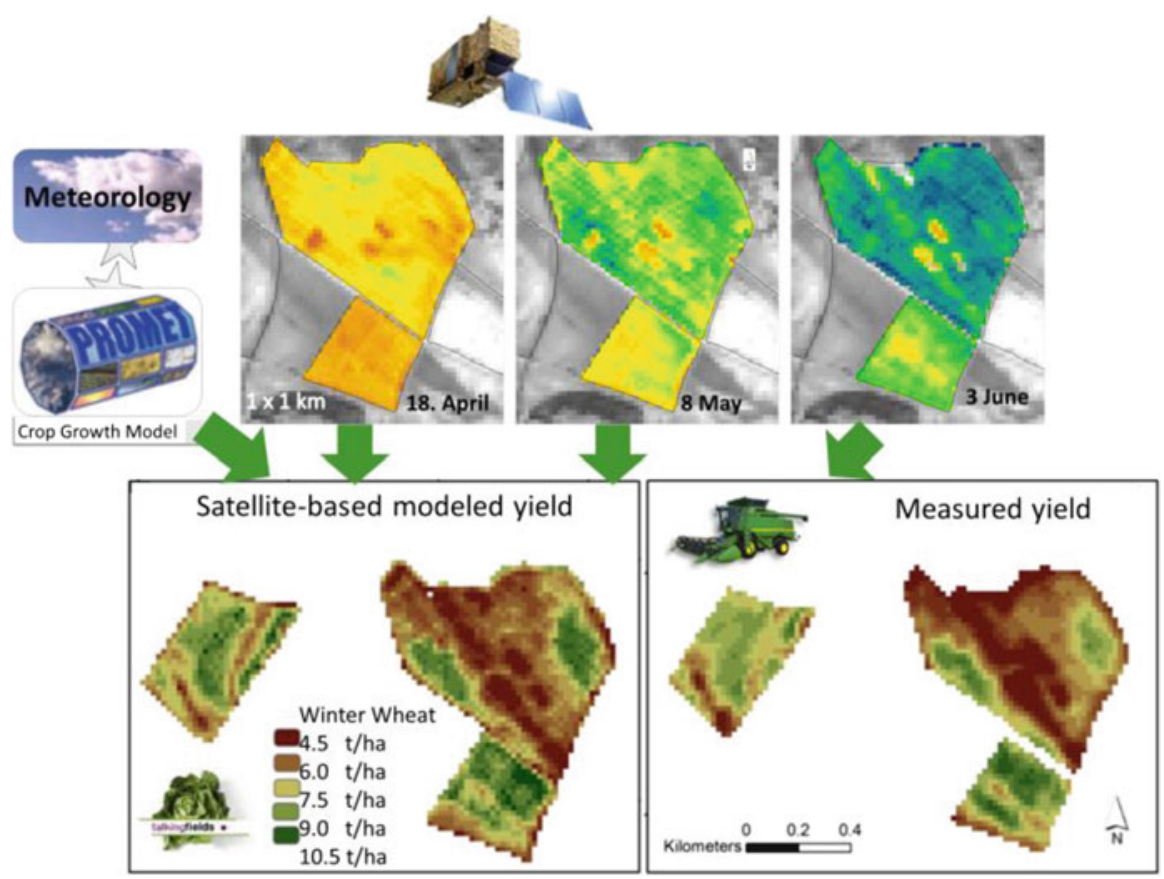

Fig. 3 Data assimilation concept for generating agricultural information services; the TalkingFields Yield Map obtained using the PROMET crop growth model corresponds very well with measured yields (Hank et al. 2015)

development that not only bring the processing capacities to the data but also provide thematic dedicated analysis tools. For agricultural applications, the Food Security TEP is presently under development to fulfil this goal. The trend for fast data and information access will thus continue.

Considering the required temporal resolution, a weekly sampling interval during the vegetation period can be considered optimum for agricultural applications, the phenological development largely being covered by this frequency. However, depending on the cloud probability of the respective region, this repetition rate is hardly ever available even when combining several sensor systems. Thus, the time gaps between the remotely sensed images are bridged with the crop model simulations which also lower the minimum demand for satellite images per growing season. For yield estimates a set of four images, covering the major stages of development, is considered appropriate (Hank et al. 2013). For site-specific fertilization and harvest logistics weekly updates from satellite are still mandatory. Accordingly, the twin constellation of Sentinel-2 is important to meet the temporal requirements in agriculture. 
The vast amount of satellite data to be processed, further make it necessary that crop parameter retrieval methods are automated, although still validated in an unsupervised way, generally applicable and thus geographical transferable. Simple regressions based on spectral indices cannot fulfil this request. Accordingly, in TalkingFields the spectral information used to derive plant physiological parameters is interpreted through inversion of radiative transfer models that are based on the physical modelling of absorptions, transmissions and scattering. Especially leaf area, APAR and chlorophyll content are importance spectrally derivable crop variables, for which an adequate coverage of the visible and near infrared region is vital. Sensitivity studies with the radiative transfer model SLC (Soil-Leaf-Canopy) (Verhoef \& Bach 2007) have shown that spectral bands in the short-wave infrared substantially increases the accuracy of leaf area retrieval. Also, for a more detailed analysis, e.g. of the moisture status of the crops using multi-spectral data, a spectral extension to the short wave infrared domain is necessary.

\section{Conclusions and Outlook}

EO based services and related products have been proven to be a stable source of information with reliable quality under varying soil and weather conditions. Information products, like the TalkingFields maps, allow the farmer to more accurately react with site-specific farming techniques. More accuracy means lower production costs, as resources such as water, seeds and fertilizer are not wasted. More accurate also means more efficient in the sense of yield per fertilizer or water used. Last but not least, more accurate also means more sustainable because less fertilizer is leached to the ground water. This benefits on the one side farmers with increased economic profits. On the other side, it also serves natural resource providers such as drinking water suppliers or environmental protection agencies, resulting in both successful commercial business and as well as environmental gains. All in all, smart farming supports ecologically and economically sound agricultural management via site-specific applications - an important step towards sustainable agriculture.

For a wide acceptance, it is however needed to offer these services in an easy and integrative way, e.g. within the farmer's Farm Management Information System (i.e. the software used by the farmers to plan and document the activities on their fields). This integration also allows creating application maps for plant protection or fertilization. These application maps can be exported to the farming machinery and be directly used in combination with the GNSS-guided tractor. This integrative approach that covers the whole service chain from the satellites to the tractor terminal will largely promote the acceptance of the services by the farmers and increase their impact on sustainability. 
Sentinel-2 already marks a huge step towards better spectral coverage and operational availability of satellite data. The free and open access to Sentinel-2 data and infrastructure platforms like FS-TEP will guarantee that these data can be used by everybody around the Globe, no matter whether they are from an industrialized country or a developing country. This gives equal chances to everybody to be more sustainable in agriculture.

Future sensor development towards hyperspectral coverage will enable to more accurately derive the currently used crop variables and extend the range of parameters available to the crop growth model to further increase its accuracy especially in optimizing crop growth management (Migdall et al. 2012). This will create major improvements in the ability to fine-tune agricultural management towards sustainable yet intensive agricultural production.

Further research and development is still needed in order to expand EO capabilities and services towards comprehensive sustainable farm management, which ensures efficient, water saving irrigation, fertilizer saving fertilization, robust, limited and timely plant protection, stable vegetation cover to minimize erosion and both high quantity and high quality yield. The tightening water-food-energy nexus makes clear that EO-based sustainable farm management is a multi-parameter task. Accordingly addressing future EO mission concepts, science as well as application will need constellations of dedicated sensors, which work in synergy and feed sophisticated land surface process models, which, like in meteorology, deliver products of value for society.

\section{References}

Bach H, Migdall S, Mauser W, Angermair W, Sephton AJ, Martin-de-Mercado G (2010) An integrative approach of using satellite-based information for Precision farming: TalkingFields. Proceedings 61st International Astronautical Congress, Prague, $\mathrm{CZ}$

Hank T, Frank T, Bach H, Mauser W (2013) On the effect of multiseasonal Earth Observation availability for the assimilation-supported modelling of winter wheat, Proceedings ESA Living Planet Symposium 2013, Special Publication SP-722, Edinburgh, UK

Hank T, Bach H, Mauser W (2015) Using a remote sensing supported hydro-agroecological model for field-scale simulation of heterogeneous crop growth and yield: application for wheat in Central Europe. Remote Sens 7:3934-3965. https://doi.org/10.3390/rs70403934

Mauser W, Bach H, Hank T, Zabel F, Putzenlechner B (2012) How spectroscopy from space will support world agriculture. IGARSS2012 Munich, IEEE 2012 International Geoscience and Remote Sensing Symposium Proceedings, pp 7321-7324

Mauser W, Klepper G, Zabel F, Delzeit R, Hank T, Calzadilla A (2015) Global biomass production potentials exceed expected future demand without the need for cropland expansion. Nat Commun 6:8946. https://doi.org/10.1038/ncomms9946

Migdall S, Klug P, Denis A, Bach H (2012) The additional value of hyperspectral data for Smart Farming. IGARSS2012 Munich, IEEE 2012 International Geoscience and Remote Sensing Symposium Proceedings 
Migdall S, Spannraft K, Bach H, Hank T, Frank T, Mauser W, Burgstaller S, Tüller G, Angermaier W (2013) On-Farm Application of Operational Integrated Satellite Services, ESA Living Planet Symposium 2013, Special Publication SP-722, Edinburgh, UK

Verhoef W, Bach H (2007) Coupled soil - leaf - canopy and atmosphere radiative transfer modeling to simulate hyperspectral multi - angular surface reflectance and TOA radiance data. Remote Sens Environ 109(2):166-182

Open Access This chapter is licensed under the terms of the Creative Commons Attribution 4.0 International License (http://creativecommons.org/licenses/by/4.0/), which permits use, sharing, adaptation, distribution and reproduction in any medium or format, as long as you give appropriate credit to the original author(s) and the source, provide a link to the Creative Commons license and indicate if changes were made.

The images or other third party material in this chapter are included in the chapter's Creative Commons license, unless indicated otherwise in a credit line to the material. If material is not included in the chapter's Creative Commons license and your intended use is not permitted by statutory regulation or exceeds the permitted use, you will need to obtain permission directly from the copyright holder. 